\title{
Transformation of Higher Education from the Perspective of Ecological Civilization
}

\author{
Xiufang Zhao \\ School of Marxism, University of Jinan, Jinan, 250022, China \\ E-mail: jdzhaoxiufang@126.com
}

Keywords: Ecological Civilization; Ecological Education; Higher Education; Transformation

\begin{abstract}
There is closely relation between education and civilization, with a particular form of civilization has specific requirements for education, which ecological civilization requires education to achieve the transformation of ecological education. Higher education assumes social responsibility for cultivating "ecological person" with ecological consciousness and literacy, which also faces the inevitable choice for conversion to ecological education.
\end{abstract}

\section{Introduction}

Ecological problem has become the critical issues of human survival and development in the 21st century. United Nations clearly pointed out that education is extremely important in promoting sustainable development and increasing the capacity of people to solve the environment and development issues in the agenda in 21st century .Thus education must be incorporated into the eco-trend and ecological reconstruction, converted to the direction of ecology. In the new period of the ecological civilization higher education assumes social responsibility for cultivating "ecological person” with ecological consciousness and literacy, which also faces the inevitable choice for conversion to ecological education.

\section{Ecological education: the education support of ecological civilization construction}

The construction of ecological civilization and the sustainable development of society cannot be achieved without the support and protection of the science and technology, administrative measures, system and culture, even is inseparable from the support of education. Education is the important part of social structure, which should become one of the most active structural elements and play the necessary social function and value under the background of ecological civilization construction.

\section{A. The concept of ecological education}

Generally speaking, ecological education is the education major based on ecology, according to the spread of ecological knowledge and ecological culture, thereby increasing people's ecological consciousness, ecological quality, and shaping ecological civilization. [1]The aim of ecological education is disseminate ecological knowledge, establish the ideas of harmony, cultivate a generation after generation of population ecology, realize the maximization of hydrophilic ecological population scale, and ultimately promote the balance and development of ecology, and the harmonious coexistence in human and nature.[2]Therefore, ecological education was based on "rethinking the dominant values and behaviors today which make the world to get rid of the old beliefs and wrong ideas", [3] merged the concept of ecological adjusted the contradictions between human and nature into education, in which to expand and enrich the connotation of education, but also enhance the strength and depth of support for the social development.

\section{$B$. The value of ecological education}

Ecological civilization, which building on the basis of education, knowledge and highly technology, was emphasize the co-evolution of human and living environment. It achieved for the development of the idea of civilization, and thus required education which disseminating civilization to achieve development of the idea, namely, the construction of the ecological 
civilization needs the support of corresponding education idea and practice. Education on the construction of ecological civilization must be reconstructed in accordance with the view and spirit of the ecology from the theories, concepts, values, policies, goals, objectives, contents, and methods, etc, actively participated in solving the ecological crisis which is the contradiction between human and outsides in industrial civilization, assumed the historic responsibility for cultivating "ecological person" with ecological knowledge, spirit, wisdom and moral. And it was necessary for ecological education to the establishment of ecological consciousness, cultivation of sustainable lifestyles and construction of ecological values. Based on this, the idea and scientific practice of ecological education has the vital significance.

\section{The ecological civilization call for ecological education}

The basic issue of education is to cultivate what kind of person; the ways and means of the education should to be taken by educates' quality in expectations Society with harmonious development is not only need the instrumental person mastered certain knowledge or skills, but the harmonious person with learning ability and wisdom. And ecological education can do this. In this way, we can discuss the supporting of ecological education for ecological civilization from the view of training "ecological person" with harmonious development. The "ecological person" should have the following basic qualities: the way of thinking in the world outlook and methodology with organic system theory in ecological priority; the value orientation of values in pursuit of economic, social and ecological comprehensive benefit; the pattern of behavior characterized by overall coordination and sustainable development.

Ecological civilization construction rose series of profound changes in the way of thinking, values, lifestyles and production methods. Thus education based on this background should to achieve the goal that comprehensive improve human's ecological literacy, form the lifestyle and behavior habits adapted to the ecological civilization, which make a positive role in the evolution of the social culture to the ecological civilization. This is the special social function history responsibility that education must be assumed. Therefore improving the level of ecological civilization, ecological education must come first. Every citizen through the ecological education realized that, there is the basic obligation of modern people to optimize human ecology and natural ecology. Ecological education should be throughout the whole process in pre-school education, compulsory education in primary and secondary schools, senior high school education, vocational education, university education, and even extends to every aspects of the social education. Promoting the ecological education in the whole society can provide support for the construction of ecological civilization, which cultivates the social public to form scientific ecological values, ecological thinking and behavior pattern.

\section{Ecological education: the global consensus under the background of ecological crisis}

\section{A. The origin of ecological education}

Along with the development of productive forces and the progress of science and technology, human beings' abilities of demanding to the nature and the ecological intervention are growing; therefore the increasingly serious ecological crisis is gradually threatening the survival of mankind itself on open or covert way. In the end, ecological crisis is a profound cultural and values crisis, people are becoming more and more clearly realized that, it is the person's value orientation hidden behind of the ecological problems, so we must be by means the of education if people want to know and understand the ecological environment, protect the earth's ecological system, and achieve the knowledge and skills to prevent ecological crisis. In this awareness, ecological education came into being in the late 1960s and early 1970s. The United Nations Human Environment Conference in Stockholm in 1972, put forward the slogan of "human beings have only one earth" marking the rise of ecological education in the world scope.

Since then, the United Nations Environment Programme (UNEP) and UNESCO held a series of international conferences and published a series of programmatic document in terms of ecological protection and environmental education, which not only carried on certain standard for the purpose, object, content, teaching principles and methods on ecological education, but also comprehensive 
exposit ecological education from different angles such as economic, social, cultural and ecological, make training plan on the international ecological education, and promote ecological education in-depth development all over the world. Ecological education has become a global consensus under the background of ecological crisis.

To solve the increasingly serious ecological problems, the vast majority of countries in the world protect the natural ecological environment with successively setting up specialized agencies, adopting economic and technical and legislative means. Among them, Britain, Germany, the United States, Russia, South Africa and other countries earlier conducted fruitful ecological education; the ecological environment education has become a part of the national education plan. The United States introduce the ecological education into school education at first; popularize the basic public ecological education in colleges and universities since the 1970s. Many colleges and universities have put environmental education courses as a compulsory course for student's non-majored, with the courses also relatively complete categories in the ecological environment research subjects, including the four major courses as "the basic function of the earth's natural systems", "the continuous relevance to human activities and environment", "the practice of sustainable way of life", "the policy strategy supporting environmental sustainability". [4] Russia's education thought, it can even affect the development of human civilization whether people have and use ecological knowledge. So there is continuously ecological education from kindergarten to university in the Russian, and ecology has become one of the college entrance examination subjects. In addition, the ecological education of college in Russia has expanded from the original traditional ecology in the mentality, and taught as a kind of world view and methodology.

\section{B. Development of ecological education in China}

Development of ecological education in China also began in the 1970s, in which the primary and secondary schools began to implement regular ecological education as an important link, some universities, such as Peking University and Sun Yat-Sen University, also started the first batch of ecological and environmental protection. However, traditional ecological education confined in biology, ecology, environmental protection and other areas of expertise, the public ecological education for non-ecological professional has taken the form of elective courses in a minority of comprehensive university to the later 1980s, with the State Education Commission take the population, resources and environment into the national education in 1990s, the ecological education has been attached importance in our colleges. As the ecological education carries out extensive worldwide since 2000, Chinese universities have strengthened the efforts of building green university, increased the types and quantities of elective courses related to the ecology and environmental protection, which carried on the useful attempt and supplement for ecological education and the form of teaching. Development of ecological education in China gradually promoted to the in-depth.

After years of efforts, there had already more than60 colleges and universities in China set up environmental protection professional, and trained a large number of specialized professionals in ecology, environmental protection, and other professionals, while ecological and environmental education had also been gradually penetrated into all aspects of society, also achieved a number of results. But compared with Europe and other developed countries, the breadth and depth of public basic ecological education in colleges and universities in China are relatively lagging behind.

Due to the Ministry of education does not include ecology courses as a compulsory course of non-ecological professionals, making the ecological education curriculum in colleges and universities lack of normative and binding, full of randomness. Therefore, ecological education in China is difficult to scale, more unable to form educational atmosphere for universal education, the entire process of education and lifelong education. Leaders in government and all kinds of enterprise have faint ecological consciousness, without putting the achievements of environmental protection into the comprehensive performance of evaluation in the inspection record, so as to form the leading cadres eager for quick success and instant benefit regardless of the protection of the ecological environment. Public ecological education in higher colleges and universities has been perfected further in urgent. 


\section{Conclusion}

"Ecology is the soul of our living, is the footstone of carrying human civilization, is the deep foundation that determined the material production and the existence and long-term stable development of human society”. [5] But with the progress of science and technology, there has been serious disaster by human hand-made such as ecological destruction, newborn disease, ozone depletion, soil erosion, desertification, and so on. And along the way, people began to reflect on the mode of human society development since the Industrial Revolution. Ecological civilization came into being, conforming to the historical process of the development of human civilization and the development trend of the times.

"The realization of ecological civilization and sustainable development is not just the drill in ecology, economics and other technical aspects, but mainly a profound revolution in the cultural dimension as human values".[6] There is inseparable from the support of science and technology means and the guarantee of laws and regulations, also the strengthening of the people's awareness of ecology and the shape of ecological values when we take the road of sustainable development and construct ecological civilization; higher education adapted to ecological civilization need to create a multi-dimensional system in ecological education, achieve the own ecological steering, cultivate qualified ecological person for the construction of ecological civilization. In this sense, ecological civilization gives higher education with new connotation, and the ecological education has created a new form of higher education.

It is the inevitable choice for higher education to turn into ecological education in the era of ecological civilization. Ecological education should not only the ecology of education content, but the ecology of education itself; not only involves the popularity of ecological knowledge just like ecology and environmental protection, also commits to culture "ecological person" with ecological consciousness, ecological wisdom and ecological ethics; not just a certain discipline or professional task, but a very complex system which needs coordination and cooperation on multi-disciplinary, multi-level, multi-dimensional.

\section{Acknowledgement}

In this paper, the research was sponsored by teaching foundation of University of Jinan (Project No. ZC1119) and the Society Science Foundation of Shandong Province (Project No. 12DKSJ05).

\section{References}

[1] K.M. Liu, and L.ZH. Wei. Some thoughts on ecological education in universities. [J].Education Exploration, 2009(2) 3-4.

[2] Su Bao-mei. Cultivate ecologically population and the mission of harmonious education.[J]. Theory Journal, 2005(6) 27-30.

[3] E. Laszlo. Fateful choices: survival choices on 21st century. [M].The Sumerian, Peking, 1997.130.

[4] Fang Yanming. Analysis and thinking on present situation of environment education in American's Colleges and universities, [J] Forestry Education In China, 2004(2) 61-63.

[5] B.M. Su, Z.X. Liu, and CH.M.Liu. Manifesto of harmonious ethics-----for harmonious development of living beings and abiotic existence. [J].Journal of University of Jinan (Social Science Edition), 2002(5)5.

[6] CH.J.Gao. The ecological civilization: the new dimension on the concept of civilization development 21st century. [J].Changbai Journal, 2000(1)7-9. 